\title{
Transdisciplinary Tobacco Research Center
}

National Cancer Institute

\section{Source}

National Cancer Institute. Transdisciplinary Tobacco Research Center. NCI Thesaurus.

Code C19981.

Proposed network in collaboration with National Institute on Drug Abuse (NIDA) to study tobacco use initiation and prevention, treatment and treatment of tobacco related cancers. 